\title{
Robinia Peseudoacacia L. Flavonoids in Defence of Plant against Soil Crude Oil Pollution
}

\author{
Mitra Noori", Mehry Askari, Fatima Beigi
}

Department of Biology, Arak University, Arak, 38156-8-8349, Iran

\begin{abstract}
Crude oil effects were examined on Robinia peseudoacacia L. leaf flavonoids. Ten $R$. peseudoacacia seeds cultivated in 4 treatments: $0 \%$ (control), $1 \%, 2 \%$ and 3\% crude oil in three repetitions in equal condition for 12 weeks. Leaf flavonoids examined using chromatographical methods. Results showed phytochemical changes in crude oil grown plants. Those were amount and number changes and appearance leaf flavonoids in comparison with control. This study showed flavonoids may have a protective defensive role against some environmental stresses such as crude oil pollutants and plants must have mechanisms that make them resistant to adverse environments and retain their fitness.
\end{abstract}

Keywords Crude Oil, Flavonoids, Robinia Peseudoacacia L

\section{Introduction}

Iran is one of the oil producing countries that every year a lot of oil is extracted from southern parts and refined in other areas. Crude oil is one of the most important pollution of environment that can leak into the soil during extraction, purification or transportation and it could damage the organisms of the soil, including plants and microorganisms. Since plants are immobile, they must have mechanisms that make them resistant to adverse environments and retain their fitness. Oil physical and chemical effects caused to impaired metabolism and growth plants (Treutter 2006). Crude oil is a complex material that composed of many hydrocarbons and non hydrocarbons (Richard et al 2007). Polycyclic aromatic hydrocarbons (PAHs) are persistence organic pollutants that are widely distributed in soils (Teng, et al 2010). Oil polluted soils are not nicely ventilated and decrease plant growth and development (Rowell 1997, Victor and Sadiq 2002). Oil pollutions reduce some plant growth parameters such as: plant height, leaf number, leaf surface, plant fresh and dry weight, biomass (Omosun et al 2008), photosynthetic pigments (Malallah et al 1998) and also nutrient absorption (Rosso et al 2005). Plant responds to oil pollution are different and depends on plant species, oil kind, amount and concentration, exposure times and environmental condition (Besalatpoor 2008, Spiares et al 2001, Pezeshki et al 2000, Zangh et al 2007).

Plant organisms being devoid of motility and immune system; have elaborated alternative defence strategies, involving the huge variety of secondary metabolites as tools

* Corresponding author:

m-noori@araku.ac.ir (Mitra Noori)

Published online at http://journal.sapub.org/ije

Copyright (C) 2012 Scientific \& Academic Publishing. All Rights Reserved to overcome stress constraints, adapt to the changing environment and survive (Vassconsuelo and Boland, 2007). Secondary metabolites play a major role in the adaptation of plants to the changing environment and in overcoming stress constraints. This flows for the large complexity of chemical types and interactions underlying various functions: structure stabilizing, determined by polymerization and condensation of phenols and quinines, or by electrostatic interactions of polyamines with negatively charged loci in cell components, photo-protective, related to absorbance of visible light and UV radiation due to the presence of conjugated double bonds: antioxidant and antiradical, governed by the availability of $-\mathrm{OH},-\mathrm{NH} 2$, and - $\mathrm{SH}$ groupings, as well as aromatic nuclei and unsaturated aliphatic chains, signal transuding (Edreva et al.2008).

Flavonoids are a remarkably diverse group and the most bioactive plant secondary metabolites with a vast array of biological functions, including apparent roles in stress protection (Winkel-Shirley 2002). They are commonly found in leaves, floral parts, and pollens. Flavonoids usually accumulate in the plant vacuole as glycosides, but they also occur as exudates on the surface of leaves and other aerial plant parts. Flavonoids are suggested to have many functions like flowers, fruits, and seed pigmentation, protection against UV light, defence against phytopathogens (pathogenic microorgansms, insects, animals), role in plant fertility and germination of pollen and acting as signal molecules in plant-microbe interactions (Olsen et al. 2007). They are beneficial for the plant itself as physiological active compounds, as stress protecting agents, as attractants or as feeding deterrents, and, in general, by their significant role in plant resistance (Treutter 2006, Gill and Tuteja 2010). Coberly and Rausher (2003) found that flavonoids are though to function in the plant stress response and male fertility in some, but not all, species. Also they knew to be induced by 
high light, cold stress, drought stress and heavy metals (Warren and Mackenzie 2001). Among the many functions of flavonoids at the interface between plant and environment, their activity as signals was intensively studied. Many flavonoid biosynthetic genes are induced under stress conditions. It has been found that there is considerable increase in flavonoid levels following biotic and abiotic stresses, such as sounding, drought, metal toxicity and nutrient deprivation (Wiknel-Shirley 2001). Chalker-Scott (1990) research was in understanding the roles of flavonoids in stress protection, as well as in defining the mechanisms that control the amount and varieties of flavonoids that are produced in plants in response to diverse environmental cues. The flavonols may be among the most important flavonoids in this regard, they are the most ancient and widespread of the flavonoids, synthesized even in mosses and ferns, and have a wide range of potent physiological activities (Wiknel-Shirley 2001). Noori et al (2009) studies on some fluoride polluted legume species showed changing amount and number, appearance or disappearance of leaf flavonoids in comparison with control. Also $\mathrm{Zn}$ effects studies on Coronilla varia flavonoids showed increasing total flavonoid and flavones $\mathrm{C}$ and $\mathrm{C}-/ \mathrm{O}$ glycoside number and aglycons production in polluted plants in compare to control (Noori et al 2010).

In this study effects of different concentration of crude oil were examined on Robinia pseudoacacia L. leaf flavonoids. $R$. Pseudoacacia is an arboreal tree legume species that is widely planted in Iran. Therefore selection the plant as arboreal phytoremediator can be useful for green space in Iran.

\section{Methods}

\subsection{Collection of Plant Material and Preparation of Crude Oil}

Healthy seeds of Robinia peseud oacacia L. were collected from Arak, Iran (lat. $34^{\circ} 06^{\prime} \mathrm{N}$, long. $49^{\circ} 46^{\prime} \mathrm{E}$ ) during 2009. Crude oil was obtained from Arak Oil Refinery, Iran. After preparation seeds using sterilization (Wang and Oyaizu 2009) and scarification (Finch-Savage and Leubner-Metzger 2006) ten seeds cultivated in 4 treatments: $0 \%(\mathrm{SRp} 1=$ control), 1\% (SRp2), 2\% (SRp3) and 3\% (SRp4) crude oil in three repetitions. Pot trials were conducted in a Conviron controlled environment system (temperature: $23 \pm 2^{\circ} \mathrm{C}$ night, $26 \pm 2^{\circ} \mathrm{C}$ day, photoperiod: $12 \mathrm{hr}$. light, $12 \mathrm{hr}$. dark, intensity of light: 3500-4500 Lux and irrigation: natural water 3 times for a week) for 12 weeks. Leaf flavonoids of control and treated plants examined and compared using two dimensional paper chromatography (2-DPC) and thin layer chromatography (TLC) methods.

\subsection{Flavonoid Compounds}

\subsubsection{Extraction of the Plant Material}

For a comparative analysis of the flavonoids, small extracts of all the accessions were prepared by boiling $200 \mathrm{mg}$ of powdered air dried leaf material for $2 \mathrm{~min}$ in $5 \mathrm{ml}$ of $70 \%$ EtOH. The mixture was cooled and left to extract for $24 \mathrm{~h}$. The extract was then filtered, evaporated to dryness by rotary evaporation at $40^{\circ} \mathrm{C}$, and taken up in $2 \mathrm{ml}$ of $80 \% \mathrm{MeOH}$ for analysis by (2-D PC).

\subsubsection{Flavonoid Analysis by 2-Dimensional Paper Chromatography (2-D PC)}

For the detection of flavonoids, ca $20 \mu \mathrm{l}$ of each of the small extracts was applied to the corner of a quarter sheet of Whatman No 1 chromatography paper as a concentrated spot (10 applications of $2 \mu \mathrm{l})$. The chromatogram for each sample was developed in BAW (n-BuOH-HOAc-H2O=4:1:5; V/V; upper layer), 1 st direction, and $\mathrm{HOAc}(=15 \%$ aqueous acetic acid), 2nd direction, with rutin (= quercetin 3-O-rutinoside) as a standard. After development, the chromatograms were viewed in long wave UV light (366 nm) and any dark absorbing and fluorescent spots were marked. $\mathrm{Rf}$-values in BAW and $15 \%$ HOAc were calculated.

\subsubsection{Methods of Identification of the Flavonoids}

When sufficient amounts of purified flavonoids had been obtained, as in the case of the flavonoids from all control and treated plants, they were identified by means of UV spectroscopy using shift reagents to investigate the substitution patterns of the flavonoids (Mabry et al., 1970; Markham, 1982) and by acid hydrolysis to identify the aglycone (see below). Cochromatography with standards was also performed where possible. Flavonoid standards available for comparison during the study were rutin, kaempferol, quercetin, myricetin, apigenin and luteolin (all obtained commercially, rutin from Merck, apigenin and luteolin from Sigma and the rest from Fluka).

\subsubsection{Acid Hydrolysis and Identification of Flavonoid Aglycones}

A small amount of each purified flavonoid (ca $0.5 \mathrm{mg}$ ) was dissolved in $0.5 \mathrm{ml}$ of $80 \% \mathrm{MeOH}$ in a test tube. To this sample $2 \mathrm{ml}$ of $2 \mathrm{M} \mathrm{HCl}$ were added and the mixture was heated in a water bath at $100^{\circ} \mathrm{C}$ for $0.5 \mathrm{~h}$. The solution was cooled, $2 \mathrm{ml}$ of EtOAc were added and thoroughly mixed with the aqueous layer using a whirley mixer. The upper EtOAc layer was removed with a pipette, evaporated to dryness, dissolved in $0.5 \mathrm{ml}$ of $\mathrm{MeOH}$ and applied as spots on thin layer chromatograms (cellulose). The TLC plates were run in three solvents alongside standards to identify the aglycone moiety (Harborne 1998).

\section{Results}

Leaf flavonoid profiles show a wide variety between control and polluted samples. Table 1 shows two- dimensional paper and thin layer chromatographically data of grown Robinia peseudoacacia L. in four treatments: $0 \%$ (SRp1=control), 1\% (SRp2), 2\% (SRp3) and 3\% (SRp4) 
crude oil. Also Figure 1 shows stacked column with a 3-D visual effect histogram for comprising leaves flavonoids data (number of total leaf flavonoids, occurrence and concentrations of rutin, quercetin, kaempferol and myricetin). Total flavonoid and flavonoid sulphates numbers increased in grown 3\% crude oil samples in comparison with control and two other treatments. There are not any kaempferol and rutin in control but both the flavonoid compounds occurred in polluted samples. Also aglycons production was observed in SRp3 and SRp4 samples, while control and SRp2 lacked.

\section{Comprising leaf flavonoids data using 2- DPC \& TLC of studied Robinia} pesudoacacia $\mathbf{L}$.

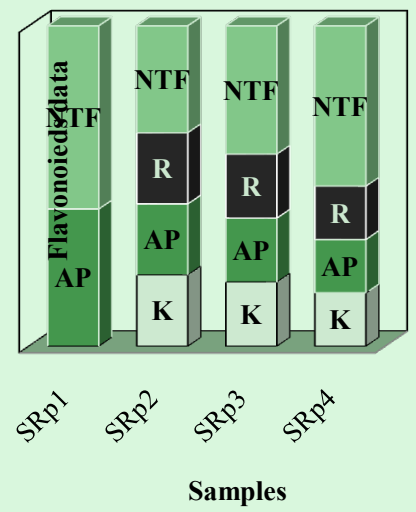

Figure 1. Stacked column with a $3-D$ visual effect histogram for comprising leaves flavonoids data using 2-dimensional paper and thin layer chromatography of 12 weeks old cultivated Robinia peseudoacacia L. in four treatments: $0 \%$ (control), $1 \%, 2 \%$ and $3 \%$ crude oil. Scored characters for drowing 3-D column histogram in Excel based on Table 1 data: -0 (non flavonoid), + 1 (few flavonoid), ++ 2 (high concentration of flavonoid)

\section{Discussion and Conclusions}

Table 1 and Figure 1 show a wide variation in leaf flavonoid profiles in all studied samples. Based on Coberly and Rausher (2003) studies, flavonoids are though to function in the plant stress response and male fertility in some, but not all, species. Also they knew to be induced by high light, cold stress, and heavy metals (Coberly and Rausher 2003). Since plants are immobile, they must have mechanisms that make them resistant to adverse environments and retain their fitness. Frost hardiness and drought resistance were sometimes attributed to flavonoids or other phenolic compounds with respect to functions in the cell wall and at membranes (Treutter 2006). Some researchers hypothesized that anti- oxidant flavonoids have protective functions during drought stress. Flavonoids may also help plants to live on soils that are rich in toxic metals such as aluminium (Barcelo and Poschenrieder 2002). Among the many functions of flavonoids at the interface between plant and environment, their activity as signals was intensively studied. Flavonoids are also beneficial for the plant itself as physiological active compounds, as stress protecting agents, as attractants or as feeding deterrents, and, in general, by their significant role in plant resistance (Treutter 2006, Gill and Tuteja 2010).

Increasing total flavonoid number in SRp4 sample and producing aglycone in SRp3 and SRp4 in comprising with SRp1 (control) and SRp2 show the drastic changes in flavonoids from control to polluted samples. The appearance of the kaempferol and rutin in all of polluted Robinia peseudoacacia (SRp2, SRp3 and SRp4) in response to the crude oil pollution stress are noteworthy (Table 1 and Figure 1). Noori et al (2009) studies on some fluoride polluted legume species showed changing amount and number, appearance or disappearance of leaf flavonoids in comparison with control. They showed the number of total flavonoids increased in fluoride polluted Robinia peseudoacacia leaves compare to control. Also Kaempferol, rutin and myricetin are not found in control but all three flavonoid compounds were present in polluted samples (Noori et al 2009). These results consisting of total flavonoid number increasing and rutin and Kaempferol producing in polluted Robinia peseudoacacia compare to control confirm that flavonoids have to play a role in protecting against environmental pollutions. There are many interactive effects of several concurrent stresses from environmental pollutants. Therefore ecological studies are more complex interrelationship between plants and pollutions. The flavonoid synthesis varies and in induced by some ecological factors such as pollutions suggested as a mimic of biotic stressors (Treutter 2006). Finally more work is needed and progress continues to be made in understanding the roles of flavonoids in stress protection, as well as in defining the mechanisms that control the amount and varieties of flavonoids that are produced in plants in response to diverse environmental cuse (Chalker-Scott 1999). It is believed that crude oil pollutant inhibited or activated some necessary enzymes for flavonoid compound synthesis. In this study, it is clear that variation in leaf flavonoid profiles in studied polluted plants is a response to crude oil pollutants and they may have a protective defensive role against crude oil pollution?

Table 1. Two-dimensional paper and thin layer chromatographically data of grown Robinia peseudoacacia $\mathrm{L}$. in four treatments: $0 \%$ (control), $1 \%, 2 \%$ and $3 \%$ crude oil

\begin{tabular}{|c|c|c|c|c|c|c|c|c|}
\hline \multirow{2}{*}{ Samples } & Crude & Total & \multicolumn{2}{|c|}{ Flavonoid type } & \multicolumn{3}{c|}{ Identification } \\
\cline { 4 - 9 } & iil \% & flavonoids & Flavone C- and C-/O-glycoside & Flavonoid sulphate & Aglycone & Kaemferol & Apigenin & Rutin \\
\hline SRp1 & $0 \%$ & 4 & 1 & 3 & 0 & $*_{-}$ & ++ & - \\
\hline SRp2 & $1 \%$ & 3 & 1 & 2 & 0 & + & + & + \\
\hline SRp3 & $2 \%$ & 3 & 1 & 2 & 1 & + & + & + \\
\hline SRp4 & $3 \%$ & 5 & 1 & 4 & 1 & + & + & + \\
\hline
\end{tabular}

$*_{-} 0$ (non flavonoid), +1 (few flavonoid), ++2 (high concentration of flavonoid) 
Our examination results showed that changing amount and number, appearance or disappearance of leaf flavonoids in comparison with control are the plant responses to the crude oil pollution stress. The appearance of the kaempferol and rutin and also aglycosn producing in polluted plants in reaction to oil pollution are noteworthy. It is believed that flavonoids have to play a defensive role in protecting against environmental pollutions and pollutant inhibited or activated some necessary enzymes for flavonoid compound synthesis. But more work is needed for revealing and understanding mechanism of flavonoids roles in stress protection.

\section{ACKNOWLEDGEMENTS}

The authors would like to thank of Arak University Research and Technology Assistant and also Biology Department in Arak University.

\section{REFERENCES}

[1] BARCEL'O J \& POSCHENRIEDER C. 2002. Fast root growth responses, root exudates, and internal detoxification as clues to the mechanisms of aluminium toxicity and resistance: A review. Environ. Exp. Botany, 48: 75-92

[2] BESALATPOUR AA, HAJABBASI MA, KHOSHGOFTARMANESH AH \& AFYUNI M. 2008. Remediation of petroleum contaminated soils around the Tehran oil refinery using Phytostimulation method, J. Agric.Sci. Natur. Resour., 44: $13-23$

[3] CHALKER-SCOTT L. 1990. Environmental significance of anthocyanins in plant stress responses, Photochem. Photobiol., 70: $1-9$

[4] COBERLY LC \& Rausher MD. 2003. Analysis of a chalcone synthase mutant in Ipomea purpurea reveals a novel function for flavonoids: amelioration of heat stress, Molecular Ecology, 12: 1113-1124

[5] EDREVA A, VELIKOVA V, TSONEV T, DAGNON S, GUREL A, AKTAS L \& GESHEVA E. 2008. Stress-protective role of secondary metabolites: diversity of functions and mechanisms, Plant physiology, 34: 67-78

[6] FINCH-SAVAGEi WE \& LEUBNER-METZGER GL. 2006. Seed dormancy and the control of germination, New Phytologist, 171: 501-523

[7] GILL SS \& TUTEJA N. 2010. Reactive oxygen species and antioxidant machinery in abiotic stress tolerance in crop plants, Plant Physiology and Biochemistry, 48: 909-930

[8] HARBORNE JB. 1998. Phytochemistry Methods, 3rd ed. Chapman and Hall, London

[9] MABRY TJ, MARKHAM KR \& THOMAS MB. 1970. The Systematic Identification of Flavonoids, Springer Verlag, Berlin

[10] MALALLAH G, AFZAL M, KURIAN M, GULSHAN S \& DHAMI MS I. 1998. Impact of oil pollution on some desert plants, Journal of Environment international, 24 (8): 919-924
[11] MARKHAM KR. 1982. Techniques of Flavonoid Identification, Academic Press, London

[12] NOORI M, AMINI F \& FOROGHI M. 2010. Zn effects on flavonoid compounds of Coronilla varia L., 16th National and 4th International Conference of Biology, Ferdowsi University of Mashhad, Mashhad, Iran, 14-16 September 2010, p. 1380

[13] NOORI M, MALAYERI B and JAFARI M. 2009. Determination of Fluoride and its effects on flavonoides in some legumes, Toxicol. And Environ. Chem., 91 (3): 409-418

[14] OLSONI PE, CASTRO A, JOERN MM, DUTEAU NAH, PILON-SMITS EF \& REARDON K. 2007. Comparison of Plant families in a greenhouse phytoremediation study on an aged polycyclic aromatic hydrocarbon-contaminated soil, Journal of Environ.Qual., 36: 1461-1469

[15] OMOSUN G, MARKSON AA \& MBANASOR O. 2008. Growth and Anatomy of Amaranthus Hybridus as Affected by Diferrent Crude Oil Concentrations, American-Eurasian Journal of Scientific Research, 3 (1): 70-74

[16] PEZESHKI SR, HESTER MW, LIN Q \& NYMAN JA. 2000. The effects of oil spill and clean-up on dominant US gulf coast marsh macrophtes (Review), Environmental Pollution, 108: $129-139$

[17] RICHARD BG, GLENN SF, CHRISTOPHER MR \& ROBERT KN. 2007. Oil Spill Source Identification by Comprehensive Two-Dimensional gas Chromatography (GC*GC) IN: Oil Spill Environmental Forensics: fingerprinting and source, Eds: WANG Z, STOUT S, 169-206

[18] ROSSO PH, PUSHNIK JC, LAY ML \& USTIN S. 2005. Reflectance properties and physiological responses of Salicornia virginica to heavy metal and petroleum contamination, Journal of Environmetal Pollution, 137: 241-252

[19] ROWELL MJ. 1977. The effect of crude oil spills on soils, A Review of Literature, In: The reclamation of agricultural soils after oil spills, TOOGOOD JA. (Ed.). Part 1, Edmonton, 1-33

[20] SPIARES JDE, KENWRTHY K \& RHYKERD R. 2001. Emegence and Height of Plants Seeded in Crude Oil Contaminated Soil, Texas Journal of Agriculture and Natural Resources, 14: 37-46

[21] TENG Y, SHEN Y, LUO Y, SUN X, SUN M, FU D, LI Z \& CHRISTIE P. 2010. Influence of Rhizobium meliloti on phytoremediation of polycyclic aromatic hydrocarbons by alfala in an aged contaminated soil, Journal of Hazardous Materials, 10: 1-29

[22] TREUTTER D. 2006. Significance of flavonoids in plant resistance. Springer-Verlag, Environmental Chemistry Letters, $4: 147-157$

[23] VASCONSUELO A \& BOLAND R. 2007. Molecular aspects of the early stages of elictition of secondary metabolites in plants, Plant Sci., 172: 861-875

[24] VICTOR JO \& SADIQ AO. 2002. Effects of spent engine oil on the growth parameters chlorophyll and protein levels of Amaranthus hybridus L., Journal of The Environmentalist, 22: $23-28$

[25] WANG YX \& OYAIZU H. 2009. Evaluation of the phytoremediation potential of four plant species for dibenzofuran-contaminated soil, Journal of Hazardous Materials, 168: 760-764 
[26] WARREN J \& MACKENZIE S. 2001. Why are all color combinations not equally represented in as flower-colour polymorphyism? New Phytologist, 151: 237-41

[27] WINKEL-SHIRLEY B. 2001. Flavonoid biosynthesis: a colorful model for genetics, biochemistry, cell biology and biotechnology, Plant physiol., 126: 485-493
[28] WINKEL-SHIRLEY B. 2002. Biosynthesis of flavonoids and effects of stress, current opinion in Plant Biology, 5: 218-223

[29] ZHANG CG, LEUNG KK, WONG YS \& TAM NFY. 2007. Germination, growth and physiological responses of mangrove plant (Bruguiera gymnorrhiza) to lubricating oil pollution, Journal of Environmental and Experimental Botany, 60: $127-136$ 